\title{
Genetic bypass of essential RNA repair enzymes in budding yeast
}

\author{
PATRICK D. CHERRY, ${ }^{1}$ LAURA K. WHITE, ${ }^{1}$ KERRI YORK, and JAY R. HESSELBERTH \\ Department of Biochemistry and Molecular Genetics, Program in Molecular Biology, RNA Bioscience Initiative, University of Colorado \\ School of Medicine, Aurora, Colorado 80045, USA
}

\begin{abstract}
RNA repair enzymes catalyze rejoining of an RNA molecule after cleavage of phosphodiester linkages. RNA repair in budding yeast is catalyzed by two separate enzymes that process tRNA exons during their splicing and HAC1 mRNA exons during activation of the unfolded protein response (UPR). The RNA ligase Trl1 joins $2^{\prime}, 3^{\prime}$-cyclic phosphate and $5^{\prime}$-hydroxyl RNA fragments, creating a phosphodiester linkage with a $2^{\prime}$-phosphate at the junction. The $2^{\prime}$-phosphate is removed by the $2^{\prime}$ phosphotransferase Tpt1. We bypassed the essential functions of TRL1 and TPT1 in budding yeast by expressing "prespliced," intronless versions of the 10 normally intron-containing tRNAs, indicating this repair pathway does not have additional essential functions. Consistent with previous studies, expression of intronless tRNAs failed to rescue the growth of cells with deletions in components of the SEN complex, implying an additional essential role for the splicing endonuclease. The trl1 $\Delta$ and tpt1 $\Delta$ mutants accumulate tRNA and HAC1 splicing intermediates indicative of RNA repair defects and are hypersensitive to drugs that inhibit translation. Failure to induce the unfolded protein response in trl1 $\Delta$ cells grown with tunicamycin is lethal owing to their inability to ligate $H A C 1$ after its cleavage by Ire1. In contrast, tpt1 $\Delta$ mutants grow in the presence of tunicamycin despite reduced accumulation of spliced HAC1 mRNA. We optimized a PCR-based method to detect RNA 2'phosphate modifications and show they are present on ligated HAC1 mRNA. These RNA repair mutants enable new studies of the role of RNA repair in cellular physiology.
\end{abstract}

Keywords: RNA repair

\section{INTRODUCTION}

RNA repair enzymes catalyze rejoining of an RNA molecule after cleavage of phosphodiester linkages. RNA repair is carried out by enzymes that prepare the RNA termini for ligation, ligate the termini, and "clean-up" the ligated product when required. RNA repair systems are present in all domains of life and catalyze rejoining of the $5^{\prime}$-hydroxyl and $2^{\prime}, 3^{\prime}$-cyclic phosphate products of cleavage. RNA repair catalyzes the maturation of endogenous tRNAs and mRNAs (Schwer et al. 2004), and can also counteract the action of endonucleases during inter-organismal conflicts (Amitsur et al. 1987; Nandakumar et al. 2008; Burroughs and Aravind 2016). E. coli RtcB can repair ribosomal RNA cleaved during stress by the endonuclease MazF, thereby reversing ribosomal heterogeneity and restoring translational activity to MazF-processed ribosomes (Temmel et al. 2016). The Pnkp-Hen1 RNA repair complex, which is present in more than 250 bacterial species, combines the enzymatic activities of the bacteriophage T4 RNA repair system with the Hen 1 methyltransferase, which

\footnotetext{
${ }^{1}$ These authors contributed equally to this work. Corresponding author: jay.hesselberth@gmail.com Article is online at http://www.rnajournal.org/cgi/doi/10.1261/rna. 061788.117.
}

installs a $2^{\prime}$-O-methyl group to “immunize” repaired RNA molecules against future cleavage by the same ribotoxin (Wang et al. 2015). In light of these and other recent developments in our understanding of the functional and genetic diversity of RNA ligases (Burroughs and Aravind 2016), we developed a genetic bypass of the Saccharomyces cerevisiae RNA repair system, enabling direct study of the roles of RNA repair proteins in budding yeast.

In budding yeast, $S$. cerevisiae, after tRNA intron excision, ligation of the exons is carried out in successive steps (Phizicky et al. 1986). First, the splicing endonuclease (SEN) complex cleaves the intron at two sites, creating two exon products, one with a $2^{\prime}, 3^{\prime}$-cyclic phosphate terminus and one with a $5^{\prime}$-hydroxyl terminus, and an intron product with $5^{\prime}$-hydroxyl and $2^{\prime}, 3^{\prime}$-cyclic phosphate termini that is degraded (Wu and Hopper 2014). In a second step, the two exons are ligated by the RNA ligase Trl1. Trl1 joins substrates with $2^{\prime}, 3^{\prime}$-cyclic phosphate and $5^{\prime}$-hydroxyl termini via: (i)

\footnotetext{
(C) 2018 Cherry et al. This article is distributed exclusively by the RNA Society for the first 12 months after the full-issue publication date (see http://rnajournal.cshlp.org/site/misc/terms.xhtml). After 12 months, it is available under a Creative Commons License (Attribution-NonCommercial 4.0 International), as described at http://creativecommons.org/licenses/ by-nc/4.0/.
} 
conversion of the $2^{\prime}, 3^{\prime}$-cyclic phosphate to a $2^{\prime}$-phosphate $/ 3^{\prime}$ hydroxyl; (ii) phosphorylation of the $5^{\prime}-\mathrm{OH}$; (iii) adenylylation of the $5^{\prime}$-phosphate, and (iv) nucleophilic attack on the adenylylate by the $3^{\prime}-\mathrm{OH}$, producing AMP and a new $5^{\prime} \rightarrow$ $3^{\prime}$ phosphodiester linkage with a $2^{\prime}$-phosphate (Greer et al. 1983). The $2^{\prime}$-phosphate left at the ligation junction is removed by the NAD-dependent $2^{\prime}$-phosphotransferase Tpt1, creating a canonical $5^{\prime} \rightarrow 3^{\prime}$ phosphodiester linkage (Fig. 1A; McCraith and Phizicky 1990; Culver et al. 1993).
A

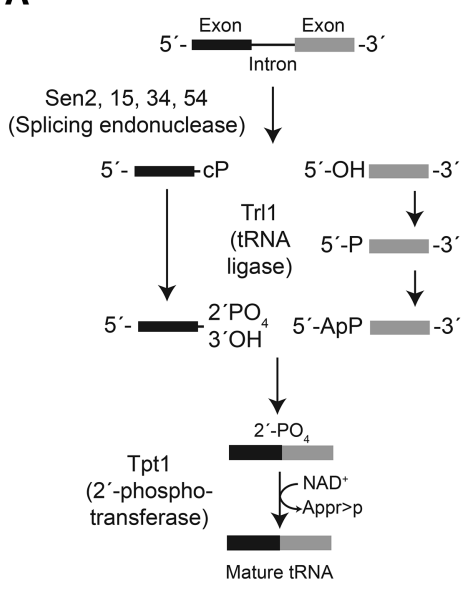

B

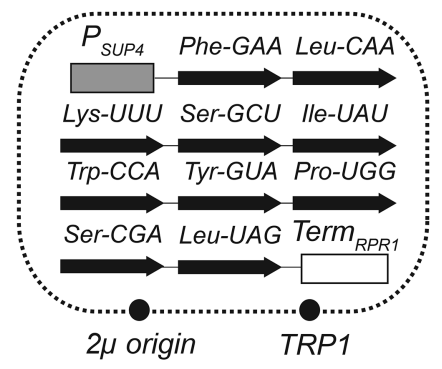

C
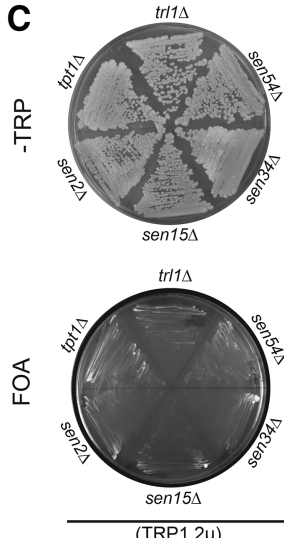

(TRP1 2 $\mu$ )

D

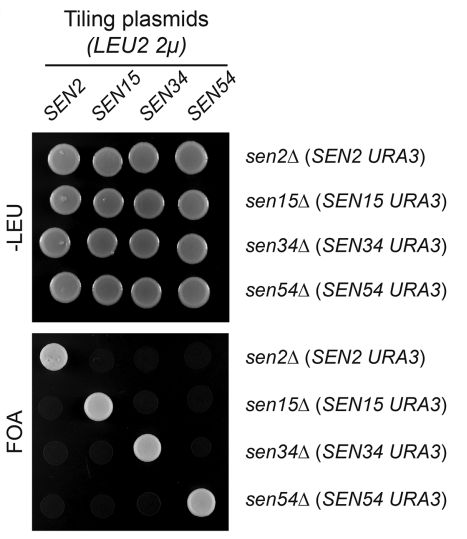

FIGURE 1. Genetic bypass of essential components of tRNA splicing with intronless tRNAs. $(A)$ Functions of tRNA splicing enzymes. Introns from pre-tRNAs are removed by the SEN complex, which contains the Sen 2 and Sen 34 endonucleases that cleave the $5^{\prime}$ and $3^{\prime}$ splice sites, respectively, as well as Sen 15 and Sen54. Following cleavage, the tRNA exons are ligated by the multifunctional RNA ligase Trl1, producing a ligated tRNA with a $2^{\prime}$-phosphate at the splice junction. Tpt1 removes the $2^{\prime}$-phosphate in an NAD ${ }^{+}$-dependent reaction, producing ADP-ribose- $1^{\prime \prime}, 2^{\prime \prime}$ cyclic phosphate and nicotinamide. $(B)$ Schematic of a plasmid encoding the $10 \mathrm{~S}$. cerevisiae tRNAs in intronless form. The tRNAs are expressed from a high-copy $2 \mu$ TRP1 plasmid containing a SUP4 promoter and terminated by the RPR1 terminator. (C) Genetic bypass of RNA repair mutants by expression of intronless tRNAs ("10×-tRNA" plasmid). Strains expressing a URA3 covering plasmid were transformed with an empty vector (TRP1 $2 \mu)$ or a high-copy plasmid encoding intronless tRNAs $(B)$. URA+TRP+ colonies (top row) were selected and struck on FOA media (bottom row), which selects against cells with the covering plasmid, to assess intronless tRNA-mediated bypass. Plates were photographed after $5-7 \mathrm{~d}$ of incubation at $30^{\circ} \mathrm{C}$. Intronless tRNAs complement deletion of TRL1 and TPT1 but do not rescue deletion of SEN components (bottom right). (D) Cells with genomic deletions of SEN genes (SEN2, SEN15, SEN34, SEN54) and a single-copy URA3 plasmid expressing the deleted gene were individually transformed with high-copy LEU2 plasmids containing the genomic locus of each of the SEN genes. $L E U+$ colonies were plated on -LEU media (top), and FOA media (bottom), to select against the covering plasmid. Only those plasmids that contain the cognate genomic locus of the deleted SEN gene were able to rescue growth on FOA (bottom).
Trl1 has a second known role in the cell: activating the unfolded protein response (UPR). Trl1 ligates the two exons of the HAC1 mRNA after cleavage by Ire1, activating the UPR Gonzalez et al. 1999). Ire1 excises an intron from the exons together, enabling its translation into a transcription factor that localizes to the nucleus and drives transcription of hundreds of stress response genes (Sidrauski et al. 1996). Yeast cells that lack Trl1 and Tpt1 and that express RNA repair enzymes from T4 bacteriophage are viable, but they exhibit low-fidelity HAC1 mRNA cleavage and ligation, suggesting the $2^{\prime}$-phosphate $/ 3^{\prime}$-hydroxyl terminus produced by the cyclic phosphodiesterase domain of Trl1 directs precise ligation (Schwer et al. 2004). Trpt1, the mammalian $2^{\prime}$-phosphotransferase, was shown to be dispensable for UPR activation in mammals (Harding et al. 2008). However, subsequent studies showed that the HSPC117/RtcB RNA ligasewhich does not create $2^{\prime}$-phosphate ligation products (Chakravarty et al. 2012) -activates the mammalian UPR (Lu et al. 2014), explaining why Trpt1 2'phosphotransferase activity is dispensable (Harding et al. 2008). The role of Tpt1 in budding yeast in the UPR has not been previously explored.

Using a genetic bypass strategy, RNA repair was previously shown to be essential only for tRNA splicing in C. elegans (Kosmaczewski et al. 2014) and in trypanosomes (Lopes et al. 2016). Using a similar strategy, we designed and tested a genetic bypass for deletion of the essential RNA repair enzymes Trl1 and Tpt1 in budding yeast and show that rescued trll $\Delta$ and tpt1 $\Delta$ cells (the "RNA repair mutants") have unique phenotypes for both tRNA splicing and HAC1 mRNA splicing during the unfolded protein response.

\section{RESULTS AND DISCUSSION \\ Genetic bypass of essential RNA repair genes in budding yeast}

Ten $S$. cerevisiae tRNA isodecoders are encoded with introns (Chan and Lowe 2009), which must be accurately processed for cells to faithfully translate messenger RNA (Hopper 2013). We adapted a strategy first documented in C. elegans 
(Kosmaczewski et al. 2014) to express these 10 tRNAs in "prespliced" form (Fig. 1B, the 10×-tRNA plasmid) and found that expression of these intronless tRNAs rescues the growth of cells with deletions in the essential genes TRL1 and TPT1 (Figs. 1C, 2A). This result is consistent with previous findings that TPT1 is essential only in the context of the generation of 2 ' - phosphorylated tRNAs by Trl1 (Schwer et al. 2004) and that a growth defect caused by TRL1 knockdown in the trypanosome Trypanosoma brucei is rescued by expressing intronless tRNA ${ }^{\mathrm{Tyr}}$ (Lopes et al. 2016).

The SEN complex cleaves introns from pre-tRNAs (Fig. $1 \mathrm{~A})$, and each component of the heterotetrameric endonuclease (Sen2, Sen15, Sen34, and Sen54) is essential for growth (Trotta et al. 1997). We created cells with single genomic deletions in each of the SEN2, SEN15, SEN34, and SEN54 genes and found that in each case cells were only viable when complemented by plasmid-mediated expression of the cognate SEN gene (Fig. 1D). We expressed the 10 prespliced tRNAs in cells containing deletions of each of the SEN genes and found that this failed to rescue deletion of any component

A

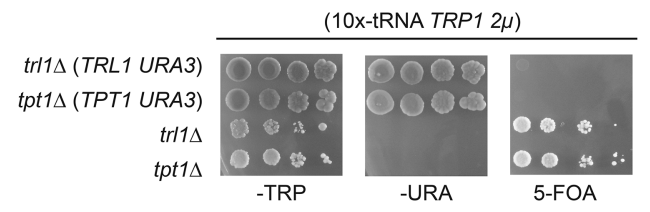

B

(10x-tRNA TRP1 $2 \mu$ )

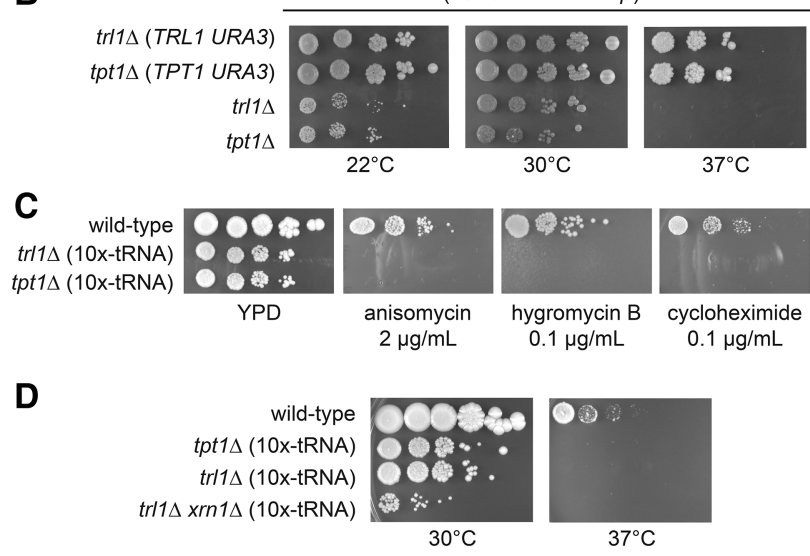

FIGURE 2. Growth phenotype of RNA repair mutants. (A) RNA repair mutants rescued by prespliced tRNAs expressed from the (10X-tRNA TRP1 $2 \mu$ ) plasmid grow on -TRP and FOA media, but not on -URA media. Plates were photographed after $3 \mathrm{~d}$ of growth at $30^{\circ} \mathrm{C}$. (B) Growth of RNA repair mutants is temperature-sensitive. Cells were serially diluted, spotted on YPD media, and incubated at the indicated temperatures. Wild-type and complemented trl1 $\Delta$ (TRL1) and tpt1 $\Delta$ (TPT1) cells grow at all temperatures, whereas bypassed $\operatorname{trl} \Delta$ and $t p t 1 \Delta$ cells fail to grow at $37^{\circ} \mathrm{C}$. (C) Sensitivity of RNA repair mutants to translational inhibitors. Cells were serially diluted and spotted on YPD media or YPD media supplemented with sublethal doses of the translational inhibitors anisomycin, hygromycin B, and cycloheximide at the concentrations indicated. Wild-type cells are viable under all conditions, whereas RNA repair mutants fail to grow in the presence of inhibitors of translation. (D) Deletion of XRN1 does not suppress the temperature-sensitive phenotype of $\operatorname{trl} 1 \Delta$ rescued with prespliced tRNAs. All plates were photographed after $3-4 \mathrm{~d}$ of incubation at $30^{\circ} \mathrm{C}$ or $37^{\circ} \mathrm{C}$. of the SEN complex (Fig. 1C), consistent with this complex having an essential function beyond splicing of pre-tRNA (Dhungel and Hopper 2012). The gene encoding the only other known substrate of the SEN complex, CBP1, is non-essential (Tsuboi et al. 2015), suggesting that the SEN complex has another essential function, possibly to process unknown RNA substrates.

\section{RNA repair mutants have defects in translation}

Genetically bypassed $\operatorname{trl} 1 \Delta$ and $t p t 1 \Delta$ cells share common growth phenotypes that may reflect translational defects in the absence of RNA repair or incomplete rescue by intronless tRNAs. We found that rescued $\operatorname{trl} 1 \Delta$ and $t p t 1 \Delta$ cells grow slowly at $30^{\circ} \mathrm{C}$ and fail to grow at $37^{\circ} \mathrm{C}$ on rich media (Fig. $2 \mathrm{~B})$. These growth defects could be due to differences in the abundance or functionality of prespliced tRNAs or due to the accumulation of endogenous intermediates of tRNA splicing. Alterations in tRNA pools and post-transcriptional modifications of specific tRNA species have been implicated in regulating translational dynamics in both prokaryotes and eukaryotes (Kirchner and Ignatova 2015), providing a possible explanation for the temperature sensitivity. Rescued $\operatorname{trl} 1 \Delta$ cells should accumulate unligated pre-tRNA half-molecules that have been cut by the SEN complex, whereas tpt1 $\Delta$ cells should accumulate spliced and ligated pre-tRNAs that retain a $2^{\prime}$-phosphate at the ligation junction (Fig. 1A). Accumulation of these molecular species could have distinct effects on translation. However, both RNA repair mutants exhibit broad sensitivity to sub-lethal doses of translational inhibitors (Fig. 2C).

It is possible that the prespliced tRNAs used to rescue $\operatorname{trl} 1 \Delta$ and tpt $1 \Delta$ mutants are suboptimal due to defects in their expression levels, amino acid charging, or post-transcriptional modification. S. cerevisiae tRNAs have an average of 13 post-transcriptional modifications per tRNA species (Phizicky and Hopper 2010), and the diverse set of modifications added to tRNAs can impact maintenance of reading frame, translational fidelity, and tRNA stability (Hopper 2013). The rapid tRNA decay pathway (RTD) comprises a quality control mechanism that degrades aberrant tRNA molecules via the $5^{\prime} \rightarrow 3^{\prime}$ exonucleases Rat 1 and Xrn 1 . Structural stability is a major determinant of RTD substrates: Both the introduction of destabilizing mutations in tRNA sequences and the deletion of modification enzymes that act to enhance tRNA stability cause temperature sensitivity in budding yeast. However, growth at $37^{\circ} \mathrm{C}$ can be rescued by compensatory mutations that restore tRNA structural stability or by deletion of the Xrn1 exonuclease (Whipple et al. 2011). Based on these prior observations, we tested whether RTD is responsible for temperature sensitivity by deleting XRN1 in a rescued trll $\Delta$ mutant and found that the double deletion, $\operatorname{trl} 1 \Delta x r n 1 \Delta$, grows no better at $37^{\circ} \mathrm{C}$ than the single $\operatorname{trl} 1 \Delta$ mutant (Fig. 2D), suggesting that the temperature sensitivity of RNA repair mutants is not a consequence of RTD. 
Whereas our results suggest that prespliced tRNAs are not rapidly degraded due to structural instability, these intronless tRNA species may still be hypomodified or otherwise suboptimal. Previous studies of tRNA introns identified two types of post-transcriptional modifications that are only added at the pre-tRNA stage, when an intron is still present. Site-specific introduction of 5-methylcytidine $\left(\mathrm{m}^{5} \mathrm{C}\right)$ or pseudouridine in the anticodon or at position 40 is dependent on the presence of the intron, and these intron-dependent modifications occur in four of the 10 intron-containing tRNAs in S. cerevisiae (Table 1; Grosjean et al. 1997). In particular, incorporation of $\mathrm{m}^{5} \mathrm{C}$ at the wobble position in the pre-tRNA ${ }^{\mathrm{Leu}(\mathrm{CAA})}$ is catalyzed by the tRNA-specific methyltransferase Trm4, and disruption of TRM4 causes sensitivity to the antibiotic paromomycin, an aminoglycoside that interferes with translational fidelity (Wu et al. 1998). This observation is consistent with our finding that RNA repair mutants rescued with prespliced tRNAs fail to grow on rich media containing low doses of the translational inhibitors anisomycin, hygromycin B, or cycloheximide (Fig. 2C). Thus, this phenotype could be indicative of hypomodification of one or more of the intronless tRNAs from the construct. Alternatively, it is possible that bypass of $\operatorname{trl} 1 \Delta$ and $t p t 1 \Delta$ with intronless tRNAs provides a complete rescue of tRNA splicing, but causes reduced fitness due to an additional but nonessential role of RNA repair related to translation.

\section{RNA repair mutants accumulate intermediates and products of tRNA splicing}

To evaluate the ability of cells lacking RNA repair to produce mature tRNAs, we analyzed the processing of tRNA ${ }^{\operatorname{Ile}(\mathrm{UAU})}$ by northern blot using total RNA from rescued $\operatorname{trl} 1 \Delta$ and tpt $1 \Delta$ cells, unshuffled control strains, wild-type, and $x r n 1 \Delta$ mutants. Wild-type, trl1 $\Delta$ (TRL1), and tpt1 $\Delta$ (TPT1) cells have expected tRNA processing intermediates, including primary transcript (145 nt), pre-tRNA with $5^{\prime}$ - and $3^{\prime}$-processing by RNaseP, Rexl, RNase Z, and Lph1 (136 nt), mature tRNA at $76 \mathrm{nt}$, excised intron at $60 \mathrm{nt}$, and $5^{\prime}$-exon at $38 \mathrm{nt}$
(Fig. 3A,B). Total RNA from trl1 $\Delta$ mutants complemented with intronless tRNAs contains a band of the same size as mature tRNA from wild-type controls, and this tRNA must arise from the intronless tRNA construct because these cells cannot ligate exons processed from genomic intron-containing tRNAs (Fig. 3A, lane 4). Cells that contain the prespliced tRNA plasmid exhibit high molecular weight species to which the northern probe hybridizes, which are likely tandem tRNA transcripts that are not completely processed. This result is consistent with the construct functioning as a single transcriptional unit, owing to its design with a single SUP4 Pol III promoter and RPR1 Pol III terminator; additionally, the intronless tRNA genes may also be transcribed individually via internal promoters (Galli et al. 1981).

The $S$. cerevisiae genome contains tRNA genes at varying copy numbers (Table 1; Chan and Lowe 2009), raising the possibility that rescue by a high-copy plasmid expressing intronless tRNAs could alter the levels of specific tRNA isodecoders. To assess the ability of the genetic bypass to produce quantities of tRNAs similar to those found in wild-type cells, we performed northern blotting with probes hybridizing to the $5^{\prime}$ exons of tRNAs with varying genomic copy number. In the case of low copy number, tRNA ${ }^{\text {Ile(UAU) }}$ is encoded at two copies per genome, and the intronless tRNA plasmid produces quantities of mature tRNA ${ }^{\mathrm{Ile}(\mathrm{UAU})}$ similar to wild-type cells (Fig. 3A, lane 1 versus 4 and 5). In contrast, the isodecoders tRNA $^{\text {Tyr(GUA) }}$ tRNA $^{\text {Leu(CAA) }}$, tRNA $^{\text {Phe(GAA) }}$, and tRNA ${ }^{\text {Pro(UGG) }}$ are encoded in the genome at relatively high copy number $(8,10,10$, and 10 copies, respectively) (Table 1$)$. The intronless tRNA plasmid produces tRNA ${ }^{\text {Tyr(GUA) }}$ and tRNA ${ }^{\text {Phe(GAA) }}$ at abundances similar to wild-type (Fig. 3C,D, lane 1 versus 4 and 5), but the plasmid fails to produce equivalent amounts of tRNA $^{\text {Leu(CAA) }}$ and tRNA ${ }^{\text {Pro(UGG) }}$ (Fig. 3E,F, lane 1 versus 4 \& 5). These results show that there is not a monotonic relationship between copy number in the genome and the ability of the intronless tRNA plasmid to produce wild-type quantities of each tRNA. However, these results do not comment on the modification status of intronless tRNAs. Furthermore, the discrepancy in quantities of tRNA ${ }^{\mathrm{Leu}(\mathrm{CAA})}$ and tRNA ${ }^{\text {Pro(UGG) }}$ produced by the intronless tRNA plasmid

TABLE 1. Intron-containing tRNA copy number (Chan and Lowe 2009) and intron-dependent modifications (Grosjean et al. 1997) in S. cerevisiae

\begin{tabular}{lccc}
\hline tRNA species & Copy number & Intron length $(\mathrm{nt})$ & Intron-dependent base modifications \\
\hline tRNA-Ser(CGA) & 1 & 19 & \\
tRNA-Ile(UAU) & 2 & 60 & Pseudouridine, positions 34 and 36 \\
tRNA-Leu(UAG) & 3 & 19 & \\
tRNA-Ser(GCU) & 4 & 19 & \\
tRNA-Trp(CCA) & 6 & 34 & Pseudouridine, position 35 \\
tRNA-Lys(UUU) & 7 & 23 & 5-methylcytidine, position 35 \\
tRNA-Tyr(GUA) & 8 & 32 & 5 -methylcytidine, position 40 \\
tRNA-Leu(CAA) & 10 & $18-19$ & \\
tRNA-Phe(GAA) & 10 & $30-33$ & \\
tRNA-Pro(UGG) & 10 & &
\end{tabular}


A
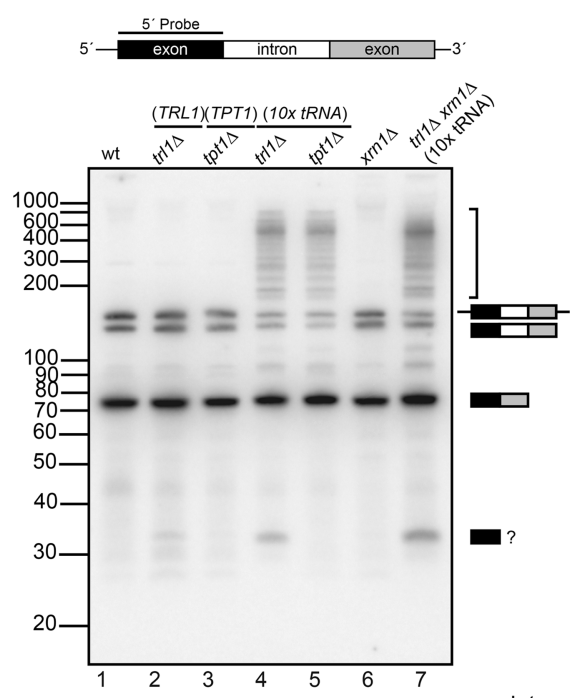

SCR1

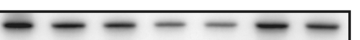

$\begin{array}{lllllll}\text { Intron Density: } 1.0 & 3.0 & 0.7 & 46.8 & 1.3 & 6.3 & 22.0\end{array}$

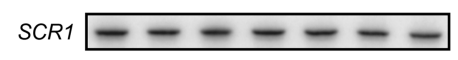

D tRNA-Phe-GAA

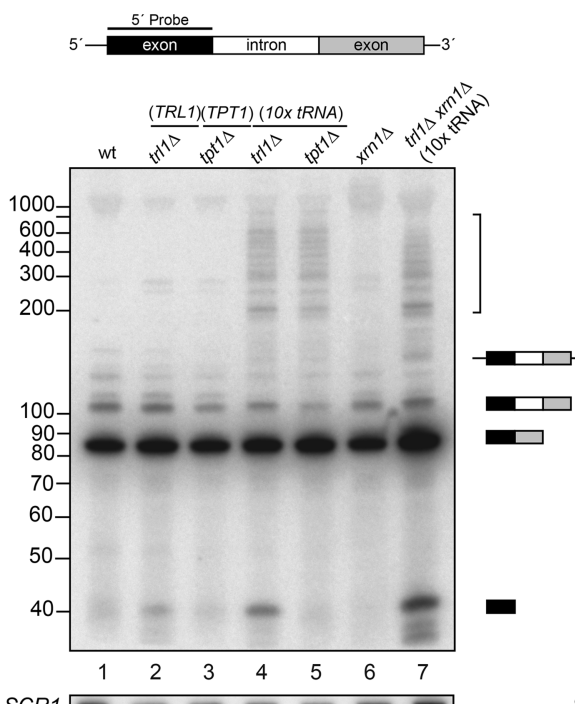

E
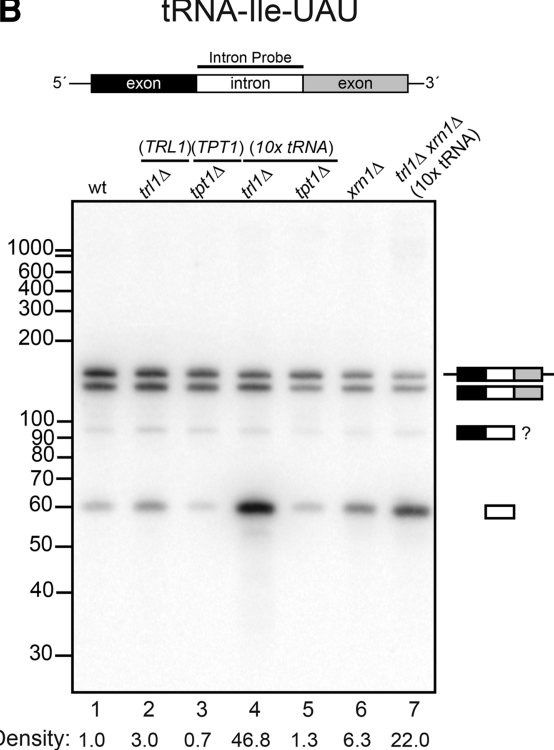

tRNA-Leu-CAA
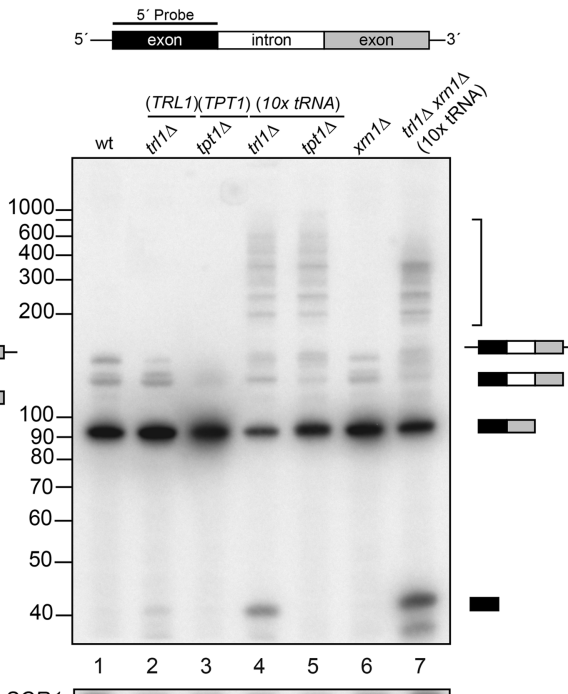

C
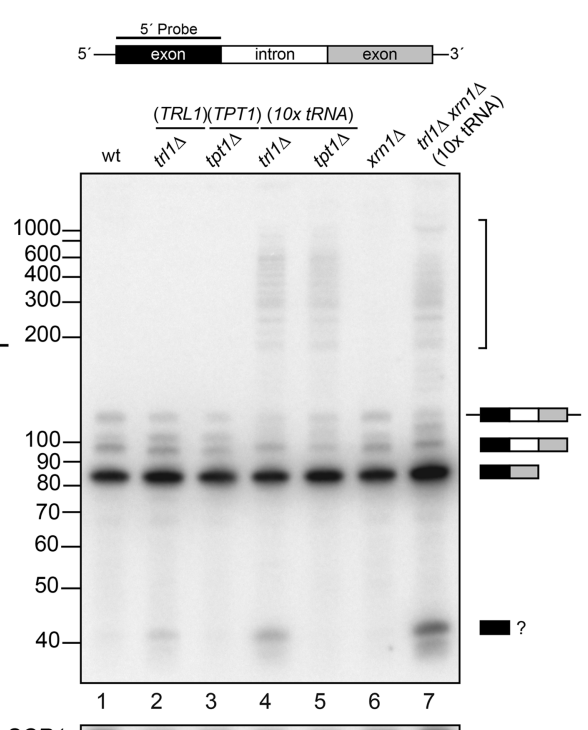

SCR1 $-\cdots-\cdots$

$\mathbf{F}$

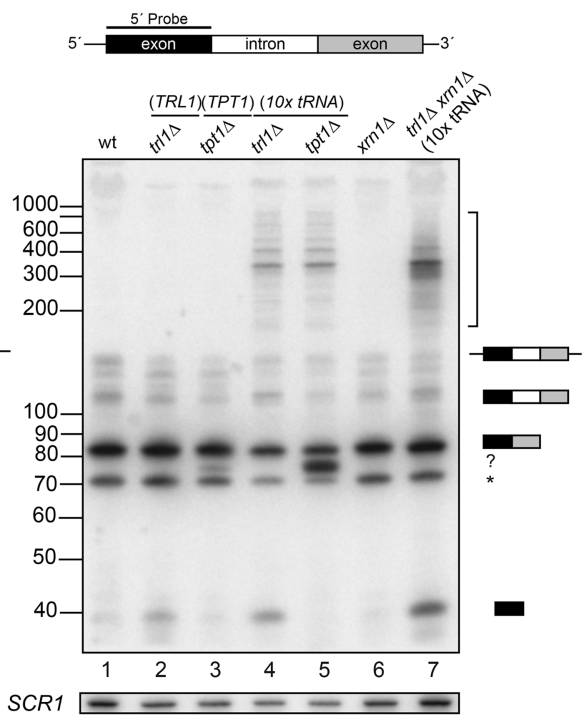

FIGURE 3. tRNA processing phenotypes of RNA repair mutants. Diagrams of tRNA primary structure, annotations, and probe locations are depicted next to each northern blot. SCR1 loading control blots are below, and were the basis of loading for each lane. (A) Northern blot using probe that hybridizes to the $5^{\prime}$-exon of tRNA ${ }^{\text {Ile(UAU) }}$ identifies preprocessed tRNA intermediates derived from primary transcripts of intronless tRNAs (lanes 4,5, and 7 , bracket annotation), as well as intermediates arising from the intron-containing endogenous tRNAs (at $\sim 150 \mathrm{nt}$ ). Each strain produces mature tRNAs $(\sim 76 \mathrm{nt})$. The trl1 $\Delta$ mutant (lane 4$)$ is unable to ligate $\mathrm{tRNA}{ }^{\mathrm{Ile}(\mathrm{UAU})}$ exons arising from chromosomal copies of the gene, and thus mature tRNAs in these cells occur from processing of the intronless tRNA transcript. A band at $232 \mathrm{nt}$ in lanes 4 and 7 is likely a product of SEN cleavage of chromosomally encoded intron-containing tRNAs that are not re-ligated. $(B)$ Northern blot with probe to tRNA ${ }^{\text {Ile(UAU) }}$ intron shows increased accumulation of the intron in $\operatorname{trl} 1 \Delta$ mutants (lanes 4 and 7), as well as in $x r n 1 \Delta$ and in double deletion trl1 $\Delta x r n 1 \Delta$ mutants (lanes 6 and 7 , respectively). A band at $\sim 90 \mathrm{nt}$ putatively represents $5^{\prime}$-exon/intron (question mark). Densitometry quantifications of intron signal relative to wild-type (lane 1 ) and normalized to SCR1 signal are displayed below lane numbers. $(C)$ Northern blot with probe to the $5^{\prime}$-exon of tRNA ${ }^{\text {Tyr(GUA) }}$, a tRNA with a copy number of eight in the budding yeast genome, reveals mature tRNA bands at approximately the same intensity across wild-type (lane 1) and repair mutant strains (lanes 4 and 5). (D) Northern blot with probe to the $5^{\prime}$-exon of tRNA ${ }^{\text {Phe(GAA) }}$, a tRNA with a copy number of 10 in the genome, exhibits approximately equal density of mature tRNA band intensity in wild-type (lane 1) and deletions in RNA repair genes (lanes 4 and 5). (E) Northern blot with probe to the $5^{\prime}$ exon of tRNA ${ }^{\mathrm{Leu}(\mathrm{CAA})}$, a tRNA with a copy number of 10 in the genome, shows a decrease in mature tRNA band intensity in the trl1 $\Delta$ mutant (lane 4), and also in the tpt $1 \Delta$ mutant (lane 5), when compared to wild-type and covered strains (lanes $1-3)$. (F) Northern blot with probe to the $5^{\prime}$-exon of tRNA $^{\text {Pro(UGG) }}$, a tRNA with a copy number of 10 in the genome, reveals a decrease in mature tRNA band intensity in both $\operatorname{trl} 1 \Delta$ and $t p t 1 \Delta$ RNA repair mutants (lanes 4 and 5, respectively). All lanes show a doublet of bands, with the upper band being consistent in size with mature tRNA ${ }^{\text {Pro(UGG) }}$, and the lower band is annotated with an asterisk. Lane 5 displays a strong tpt $1 \Delta$-dependent band, annotated with a question mark. 
could contribute to the slow growth phenotype of the RNA repair mutants (Fig. 2).

The northern blot for tRNA ${ }^{\text {Pro(UGG) }}$ (Fig. 3F) reveals several additional features of interest that appear to be unique to this tRNA isodecoder. Doublet bands of spliced tRNA $^{\text {Pro(UGG) }}$, which we also detected in all strains tested, have been previously observed by denaturing polyacrylamide gel (Winey et al. 1986). The upper of these two bands has a length consistent with the $75 \mathrm{nt}$ mature $\mathrm{tRNA}^{\mathrm{Pro}(\mathrm{UGG})}$ (Chan and Lowe 2009). The lower band, 10 nt shorter, cannot be explained as an intron-containing tRNA half or processing intermediate, as the intron for tRNA ${ }^{\mathrm{Pro}(\mathrm{UGG})}$ is 31 $\mathrm{nt}$ and a processing intermediate that contained the intron and both exons would migrate at $\sim 103 \mathrm{nt}$. Because these intermediates accumulate in the RNA ligase mutant-and ligase is required for intron splicing - the prespliced tRNA construct is also competent to produce both species (i.e., the putative processing intermediate marked with an asterisk and mature tRNA). In addition, both $t p t 1 \Delta$ (TPT1) and tpt1 $\Delta$ cells (Fig. 3F, lanes 3 and 5) contain a third tRNA ${ }^{\text {Pro(UGG) }}$ band (indicated by a question mark) that accumulates to high levels in tpt $1 \Delta$ cells and is not seen in other genotypes, which may correspond to an additional tRNA species resolved via 2D PAGE analysis of tRNA from a tpt 1 conditional mutant (Spinelli et al. 1997). It is possible that this third band is derived from endogenous spliced tRNA ${ }^{\operatorname{Pro}(\mathrm{UGG})}$ that retains a $2^{\prime}$-phosphate at the splice junction in the absence of TPT1; however, the precise identity of these three species of tRNA $^{\text {Pro(UGG) }}$ remains unresolved.

In addition to analysis of mature tRNA production, we further investigated the fate of the introns from endogenous tRNA genes in the context of the RNA repair mutants. Northern blot analysis of the tRNA ${ }^{\mathrm{Ile}(\mathrm{UAU})}$ intron recapitulated the finding that decay of excised tRNA introns requires both Xrn1 and Trl1 (Wu and Hopper 2014). Bypassed trll $\Delta$ cells show an increase in levels of tRNA intron (47fold compared to wild-type, normalized to SCR1 levels), as do $x r n 1 \Delta$ cells (6.3-fold) and double mutant $\operatorname{trl} 1 \Delta x r n 1 \Delta$ cells (22-fold) (Fig. 3B, lanes 4,6, and 7). These observations are in line with kinase-mediated decay of cleaved tRNA introns, in which the $5^{\prime}$-RNA kinase activity of Trl1 (Fig. 1A) is required to phosphorylate the $5^{\prime}$-hydroxyl intron products of SEN cleavage to enable their $5^{\prime} \rightarrow 3^{\prime}$ exonucleolytic decay by Xrn1, which specifically degrades $5^{\prime}$-phosphorylated RNA substrates (Stevens 2001).

\section{RNA repair mutants have defects in unfolded protein response activation}

Induction of the unfolded protein response (UPR) requires the ligation of two exons after intron excision from the HAC1 mRNA (Gonzalez et al. 1999). We tested cells lacking RNA repair for their ability to activate the UPR. Bypassed $\operatorname{trl} 1 \Delta$ mutants fail to grow on media containing the UPR-inducing drug tunicamycin (Fig. 4A), confirming that Trl1 is required for UPR activation in response to protein folding stress (Sidrauski et al. 1996). In contrast, tpt1 $\Delta$ mutants grow equally well in the presence and absence of tunicamycin (Fig. 4A), suggesting that the $2^{\prime}$-phosphate remaining on $H A C 1$ mRNA after ligation in $t p t 1 \Delta$ cells does not interfere with its translation or that partial HAC1 translation is sufficient for UPR activation (see below). Cells with Hac1FLAG (in wild-type, $\operatorname{trl} 1 \Delta$, and $t p t 1 \Delta$ backgrounds) were also spotted onto tunicamycin containing media and had similar growth to cells with untagged Hacl, confirming that Hacl-FLAG can function in the UPR (Fig. 4A).

We corroborated the growth assay by analyzing HAC1 splicing in trl1 $\Delta$ and tpt1 $\Delta$ cells using RT-PCR (Fig. 4B). The wild-type strain catalyzes cleavage and ligation of HAC1 upon UPR stimulation with tunicamycin, whereas the trl1 $\triangle$ mutant exhibits no detectable spliced $H A C 1$ and a reduction in unspliced $H A C 1$. The decrease in unspliced HAC1 observed in lanes 4 and 6 (Fig. 4B) when compared to their tunicamycin-null control lanes can be explained by two facts: First, both strains express Ire1, the endonuclease responsible for cleaving HAC1 mRNA prior to ligation; second, the $\mathrm{Hacl}$ protein is a transcription factor that activates transcription of the $H A C 1$ gene, creating a positive feedback loop to sustain UPR activation (Ogawa and Mori 2004). When Ire1 cleaves HAC1 mRNA, but Trl1 is unavailable for ligation, Hacl protein is not translated and cells fail to activate the positive feedback loop. Then, without the newly transcribed $H A C 1 \mathrm{mRNA}$, the remaining pool of $H A C 1$ is efficiently cleaved so that the cDNAs synthesized do not contain both PCR priming sites and thus fail to amplify in this PCR assay. These simultaneous deficits could lead to a decrease in unspliced $H A C 1$ in RNA repair mutants treated with tunicamycin when compared to their null-treatment controls.

We found that $t p t 1 \triangle$ cells accumulate spliced $H A C 1$, but to a lesser extent than wild-type, suggesting that the 2 '-phosphorylated products of ligation interfere with processing or stability of the $H A C 1$ mRNA (Fig. 4B, compare lane 2 versus 6). Cells with Hacl-FLAG spliced HAC1 mRNA with the same pattern as their untagged controls (Fig. 4B). An immunoblot for Hac1-FLAG (Fig. 4C) showed that wild-type cells showed no detectable Hacl until the UPR was induced with tunicamycin, but Hac1-FLAG could not be detected in lysate from $\operatorname{trl} 1 \Delta$ or $t p t 1 \Delta$ cells.

In addition, $\operatorname{trl} 1 \Delta$ cells failed to increase expression of the chaperone KAR2 (Fig. 4D), a representative UPR-responsive gene strongly induced by Hacl transcription factor protein (Mori et al. 1992; Nikawa et al. 1996), indicating that trl1 $\Delta$ cells fail to induce UPR-responsive genes. Consistent with reduced spliced HAC1 mRNA accumulation (Fig. 4B), tpt1 $\Delta$ mutants also show reduced expression of KAR2 (Fig. 4D). However, this reduced degree of UPR induction, as observed by $H A C 1$ mRNA splicing and KAR2 expression, is nonetheless sufficient for growth of tpt $1 \Delta$ cells in the presence of tunicamycin (Fig. 4A). Despite accumulation of spliced HAC1 
A

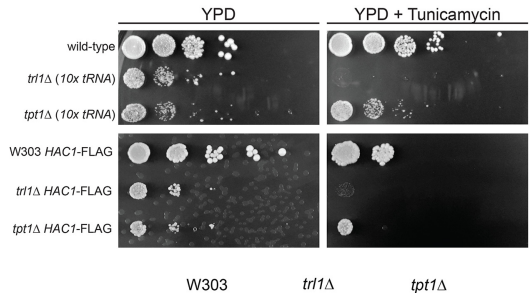

C
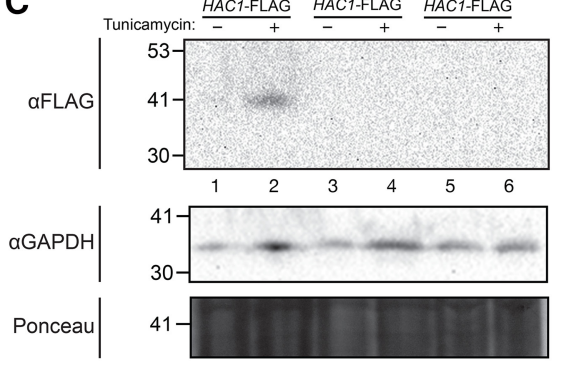

B
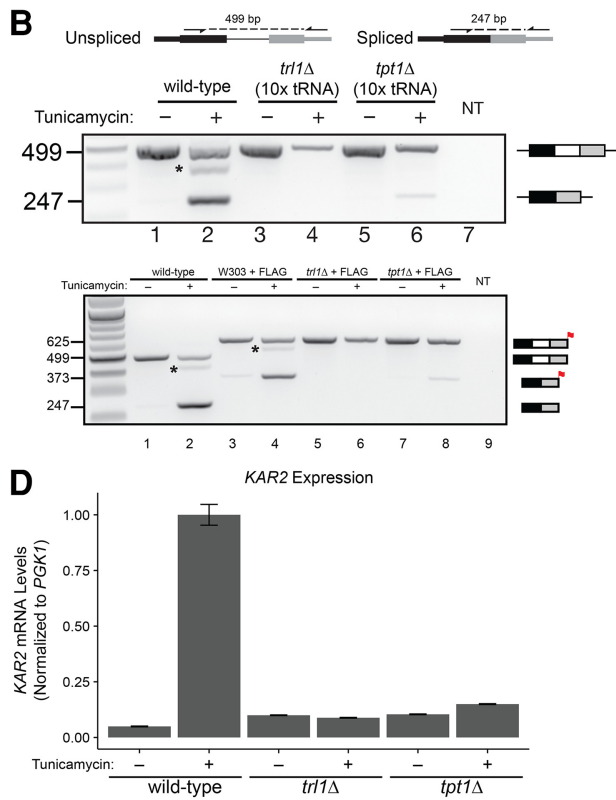

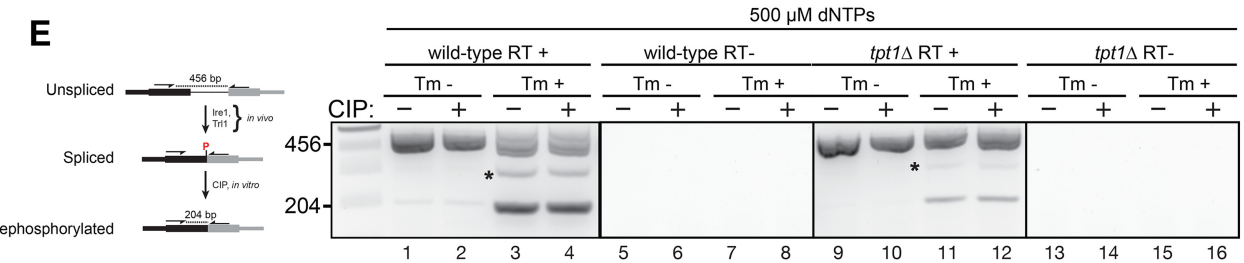

$\mathbf{F}$
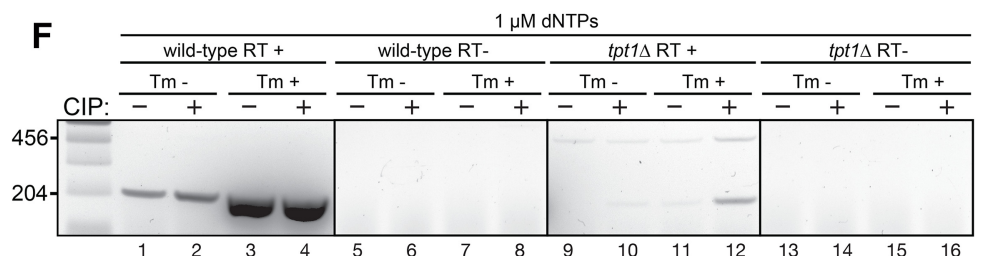

Enhanced Contrast

$1 \mu \mathrm{M}$ dNTPS tpt1 $1 \Delta \mathrm{RT}+$

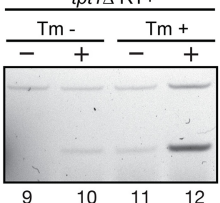

FIGURE 4. UPR-related phenotypes of RNA repair mutants. (A) Growth assay of RNA repair mutants on UPR-inducing media. Yeast cells (wildtype, $\operatorname{trl} 1 \Delta$, and $\operatorname{tpt} 1 \Delta$ ) were serially diluted and spotted onto rich media (YPD) and tunicamycin-containing media $(80 \mathrm{ng} / \mathrm{mL}$ tunicamycin) to induce the UPR. Plates were imaged after $3 \mathrm{~d}$ of growth at $30^{\circ} \mathrm{C}$. Wild-type and $t p t 1 \Delta$ cell growth is unaffected by tunicamycin, whereas $t r l 1 \Delta$ cells fail to grow on media containing tunicamycin. Serial dilution growth assays for cells of the same genetic background as above, but with $C$-terminal FLAG tags on Hac1, are shown below. (B) Analysis of $H A C 1$ splicing in RNA repair mutants. Total RNA from untreated and tunicamycin-treated wild-type, trl1 $\triangle$, and tpt $1 \Delta$ cells was analyzed by RT-PCR using primers specific for $H A C 1$, producing products at $499 \mathrm{bp}$ (unspliced HAC1) and $247 \mathrm{bp}$ (spliced HAC1). A no-template (NT) control is shown in lane 7. The proportion of spliced HAC1 upon tunicamycin treatment increases in wild-type (lanes 1 , and 2) and tpt1 $\triangle$ cells (lanes 5 and 6), and spliced $H A C 1$ is visible in RNA from both cells (lanes 2 and 6, $247 \mathrm{bp}$ ). Spliced HAC1 is undetectable in $\operatorname{trl} 1 \Delta$ cells (lane 4) upon tunicamycin treatment (lanes 3 and 4), owing to the inability of trll $\Delta$ cells to ligate HACl exons. Asterisk marks an unknown PCR product dependent on tunicamycin treatment. Cells with $C$-terminal FLAG tags of Hacl were also analyzed for splicing in the same manner (below) with a no-template (NT) control in lane 9. Reactions lacking reverse transcriptase (RT-) were negative for amplification (data not shown). (C) Hacl protein levels in RNA repair mutants. Whole cell lysates were prepared from wild-type, $\operatorname{trl} 1 \Delta$, and tpt1 $\Delta$ cells expressing C-terminal Hac1FLAG and grown in the presence and absence of tunicamycin. Lysates were analyzed by SDS-PAGE and nitrocellulose transfer followed by Ponceau $S$ staining and cross-reaction with anti-FLAG and anti-GAPDH antibodies. Scale to the left is nominal molecular mass of a protein ladder ( $\mathrm{kDa}$ ); the expected mass of Hac1-FLAG is $31 \mathrm{kDa}$. Hac1-FLAG is detected in wild-type cells upon tunicamycin addition, but is undetectable in trl1 $\Delta$ and tpt1 $\Delta$ cells. (D) Induction of the UPR-responsive KAR2 gene in RNA repair mutants. Amounts of KAR2 mRNA (normalized to PGK1 mRNA abundance) were measured by RT-qPCR in wild-type, $\operatorname{trl} 1 \Delta$, and $\operatorname{tp} t 1 \Delta$ cells in the presence and absence of tunicamycin. Error bars are $95 \%$ confidence intervals, $n$ =3. Relative abundance of KAR2 mRNA increased 20-fold in wild-type cells treated with tunicamycin, whereas the corresponding levels of KAR2 did not increase in $\operatorname{trl} 1 \Delta$ and increased 1.4-fold in tpt1 $\Delta$ cells. (E) Detection of ligated and 2'-phosphorylated HAC1 mRNA. Total RNA was treated with calf intestinal phosphatase (CIP) to remove $2^{\prime}$-phosphates (diagram) and reverse-transcribed using HAC1-specific primer under high (500 $\left.\mu \mathrm{M}\right)$ concentrations of dNTPs. The cDNA products were PCR amplified, yielding products for unspliced (456 bp) and spliced (204 bp) HAC1 mRNA. Using high dNTP concentrations, we find that splicing of $H A C 1$ in wild-type cells increases upon tunicamycin treatment (compare lanes 1 and 2 versus 3 and 4 ), similar to $B$, but is unaffected by CIP treatment (compare lanes 1 versus 2 , and 3 versus 4 ). Likewise, we find that spliced $H A C 1 \mathrm{mRNA}$ in tpt $1 \triangle$ cells increases in response to tunicamycin (cf. lanes 9 and 10 versus lanes 11 and 12), albeit to a lesser extent than wild-type cells, and is unaffected by CIP treatment (cf. lanes 9 versus 10 and lanes 11 versus 12). An asterisk marks an unknown PCR product dependent on tunicamycin treatment. $(F)$ Detection of ligated and $2^{\prime}$-phosphorylated HACl mRNA. Using low $(1 \mu \mathrm{M})$ dNTP concentrations, we find that spliced HACl is preferentially amplified in wild-type cells over unspliced HAC1 (lanes 1-4). The abundance of spliced HAC1 mRNA from wild-type cells increases in response to tunicamycin but is unaffected by CIP treatment (cf. lanes 1 versus 2 and 3 versus 4). RT-PCR analysis of HAC1 mRNA from tpt1 $\Delta$ cells reverse transcribed under low dNTP concentrations shows both unspliced and spliced forms of HAC1 mRNA, and spliced HAC1 mRNA increases in response to tunicamycin treatment (cf. lanes 10 and 12). However, in contrast to wild-type, amplification of spliced HAC1 mRNA from tpt1 $\Delta$ is strongly dependent on prior treatment with CIP. In the absence of tunicamycin and CIP treatment, spliced HAC1 mRNA is undetectable, whereas treatment with CIP enables reverse transcription (cf. lane 9 to lane 11; see panel with enhanced contrast to the right). Similarly, the abundance of spliced HAC1 mRNA from tpt1 $\Delta$ cells increases in response to tunicamycin, and its abundance is further increased upon CIP treatment (lane 11 versus 12). 
mRNA (Fig. 4B), accumulation of KAR2 mRNA (Fig. 4D) and growth on tunicamycin (Fig. 4A), we were unable to detect Hac1-FLAG by immunoblot from tpt1 $\Delta$ cells (Fig. $4 \mathrm{C})$. It is possible that the $2^{\prime}$-phosphate allows only partial translation of the spliced HAC1 mRNA $5^{\prime}$-exon, leading to production of Hacl N-terminal bZIP domain and low-level UPR activation, but precluding translation of the C-terminal FLAG epitope. Consistent with this possibility, translation of unspliced HAC1 mRNA is sufficient to restore growth on tunicamycin-containing media in the absence of the Duh1 ubiquitin ligase (Di Santo et al. 2016).

We found that tpt1 $1 \Delta$ mutants accumulate less spliced $H A C 1$, less Hac1 protein, and less KAR2 mRNA than wildtype yeast despite having a functional RNA ligase. To determine whether ligated HAC1 mRNA retains a 2 '-phosphate at the ligation junction in $t p t 1 \Delta$ cells, we adapted a reversetranscriptase-based method from previous reports that show $2^{\prime}$-phosphates inhibit reverse transcription (Schutz et al. 2010; Dhungel and Hopper 2012). We used calf intestine phosphatase (CIP) treatment, which removes $2^{\prime}$-phosphates from RNA (Fig. 4E schematic; McCraith and Phizicky 1990), and RT-PCR to test whether 2 ' -phosphates were present in ligated HAC1 mRNA. Using low concentrations of dNTPs $(1 \mu \mathrm{M})$ (Fig. 4F) and a reverse transcription primer adjacent to the expected site of $2^{\prime}$-phosphorylation, CIP treatment substantially enhanced detection of spliced $H A C 1$ mRNA in tpt1 $\triangle$ cells, but levels of amplified HAC1 in RNA from wild-type cells were unaffected, indicating that a $2^{\prime}$ phosphate remains at the ligation junction in the $H A C 1$ mRNA from tpt1 $\Delta$ cells. Reverse transcription reactions with typical dNTP concentrations $(500 \mu \mathrm{M})$ (Fig. 4E) restored amplification of unspliced HAC1 mRNA. We surmise that reduced dNTP concentrations lower the processivity of reverse transcriptase, favoring synthesis of shorter cDNA substrates. The presence of spliced HAC1 mRNA in tpt1 $\Delta$ cells in the absence of CIP treatment (Fig. 4F, lane 11) could indicate that the assay is not quantitatively sensitive to sites of $2^{\prime}$ phosphorylation or that not all molecules of ligated $\mathrm{HACl}$ mRNA retain $2^{\prime}$-phosphates despite the absence of Tpt1. In any case, $2^{\prime}$-phosphorylated RNA reduces cDNA synthesis under these conditions, enabling their detection via this RT-PCR strategy.

\section{Conclusions}

We showed the one essential function of RNA repair in budding yeast is catalyzing the ligation of tRNA halves resulting from splicing; however, the reduced-growth phenotypes of RNA repair mutants caused by various translational inhibitors, a UPR-inducing drug, and elevated temperature suggest either that the prespliced tRNAs do not function at the same efficiency/abundance as endogenously encoded tRNAs or that RNA repair is generally helpful to cells, albeit not essential. We demonstrated that "prespliced" tRNA genes are transcribed and/or processed to a size consistent with wild-type mature tRNA. Furthermore, we provided evidence of dysfunction of the UPR in both the ligase mutant and the $2^{\prime}$ phosphotransferase mutant, suggesting that $2^{\prime}$-phosphorylated HAC1 mRNA contributes to UPR induction dynamics. Lastly, we showed that RNA retaining $2^{\prime}$-phosphate residues is detectable when the enzyme responsible for removing them is deleted.

These new genetic reagents enable studies to identify other targets of RNA repair. For example, cells lacking the Tpt1 2'phosphotransferase accumulate $2^{\prime}$-phosphates at sites of RNA ligation, enabling their possible identification by methods to identify 2'-O-modifications by RNA-seq (Birkedal et al. 2015) or by affinity purification by tagging with mutant Tpt1 enzyme and biotin-NAD (Steiger et al. 2005). These approaches address the diversity of RNA repair in biology and are the subject of further study.

\section{MATERIALS AND METHODS}

\section{General methods}

Saccharomyces cerevisiae W303 strains (Table 2) were cultured in YPD and synthetic "drop-out" media (Sherman 2002) for experimental cultures and for plasmid selection, respectively. Singlecopy URA3 SEN plasmids were created by recombining SENcontaining genomic fragments from the yeast tiling collection (Jones et al. 2008) into Advanced Gateway plasmids (Alberti et al. 2007) via Gateway LR reactions (Life Technologies). Plasmid counterselection was performed on synthetic complete solid media containing 5-fluoroorotic acid (FOA, US Biologicals) $(1 \mathrm{mg} / \mathrm{mL})$. Yeast transformations were performed using a Lithium Acetate PEG-3350 Sheared Salmon Sperm protocol (Gietz and Schiestl 2007). Genotypes of yeast were confirmed by PCR using forward and reverse primers flanking the disrupted locus and outward-facing primers within the disruption cassette. Success of FOA plasmid counterselections was confirmed using RT-PCR for the shuffled gene in DNased total RNA isolated from shuffled strains and positive controls.

Experiments with tunicamycin (Sigma) treatment were performed at final concentrations of $0.08 \mu \mathrm{g} / \mathrm{mL}$ in solid media and at $2.5 \mu \mathrm{g} / \mathrm{mL}$ in liquid media, with negative controls using DMSO (solvent). Cultures were incubated at $30^{\circ} \mathrm{C}$ unless otherwise indicated. UPR inductions \pm tunicamycin were carried out for $2 \mathrm{~h}$ during exponential phase growth. For growth assays, cells were grown in YPD overnight and liquid cultures were normalized to $\mathrm{OD}_{600}=0.2$ before plating 10 -fold serial dilutions on indicated media. For translation inhibition assays, dilutions were spotted onto YPD agar supplemented with $2 \mu \mathrm{g} / \mathrm{mL}$ anisomycin (Sigma), $100 \mathrm{ng} / \mathrm{mL}$ hygromycin B (Invivogen), or $100 \mathrm{ng} / \mathrm{mL}$ cycloheximide (Sigma).

\section{Northern blotting}

Oligonucleotide probes (IDT) were designed to hybridize with RNA species to be analyzed (Table 3). Oligonucleotide probes were $5^{\prime}$ radiolabeled with $\left[\gamma^{-32} \mathrm{P}\right]$-ATP (PerkinElmer) using T4 PNK (Enzymatics), and excess unincorporated label was removed with 
TABLE 2. Strain numbers and genotypes

\begin{tabular}{|c|c|c|}
\hline Strain ID & Genotype & Source \\
\hline YJH829 & tpt1A::LEU2 (TPT1 CEN ARS URA3) & (Schwer et al. 2004) \\
\hline YJH830 & tpt1A::LEU2 (TPT1 CEN ARS URA3) (pAG424-ccdB) & \\
\hline YJH832 & tpt1A::LEU2 (TPT1 CEN ARS URA3) (pAG424-10x-tRNA) & \\
\hline YJH834 & tpt1A::LEU2 (pAG424-10x-tRNA) & \\
\hline YJH681 & $\operatorname{trl} 1 \Delta:: k a n M X(T R L 1$ CEN URA3) & (Schwer et al. 2004) \\
\hline YJH708 & trl14::kanMX (TRL1 CEN URA3) (pAG424) & \\
\hline YJH709 & $\operatorname{trl} 14:: k a n M X(T R L 1$ CEN URA3) (pAG424-10x-tRNA) & \\
\hline YJH835 & $\operatorname{tr} 11 \Delta:: k a n M X(\mathrm{pAG} 424-10 \mathrm{x}-t R N A)$ & \\
\hline YJH836 & sen2A::kanMX (SEN2 tiling block CEN ARS URA3) & \\
\hline YJH837 & 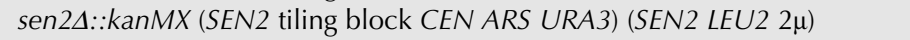 & \\
\hline YJH838 & 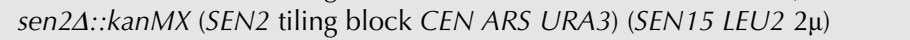 & \\
\hline YJH839 & 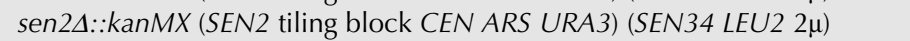 & \\
\hline YJH840 & 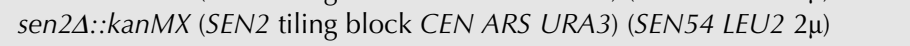 & \\
\hline YJH841 & sen15A::kanMX (SEN15 tiling block CEN ARS URA3) & \\
\hline YJH842 & 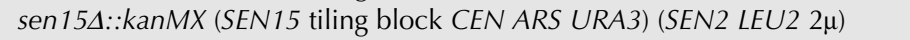 & \\
\hline YJH843 & 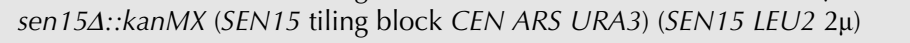 & \\
\hline YJH844 & 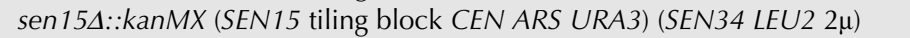 & \\
\hline YJH845 & 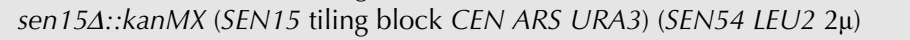 & \\
\hline YJH846 & sen34A::kanMX (SEN34 tiling block CEN ARS URA3) & \\
\hline YJH847 & 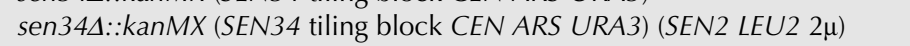 & \\
\hline YJH848 & 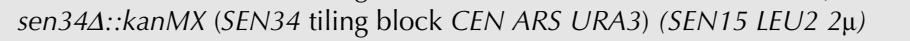 & \\
\hline YJH849 & sen344::kanMX (SEN34 tiling block CEN ARS URA3) (SEN34 LEU2 2 $\mu$ ) & \\
\hline YJH850 & 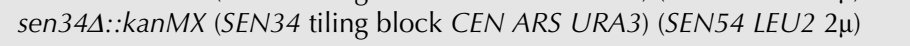 & \\
\hline YJH851 & sen54A::kanMX (SEN54 tiling block CEN ARS URA3) & \\
\hline YJH852 & 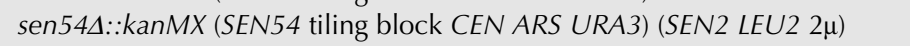 & \\
\hline YJH853 & 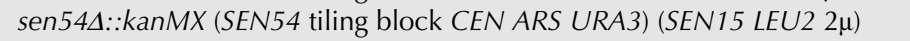 & \\
\hline YJH854 & 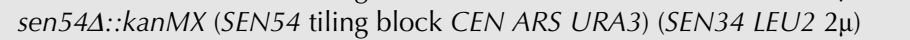 & \\
\hline YJH855 & 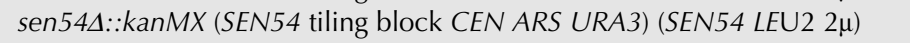 & \\
\hline YJH856 & sen2A::kanMX (SEN2 tiling block CEN ARS URA3) (pAG424-ccdB) & \\
\hline YJH857 & sen2A::kanMX (SEN2 tiling block CEN ARS URA3) (pAG424-10x-tRNA) & \\
\hline YJH858 & sen15A::kanMX (SEN15 tiling block CEN ARS URA3) (pAG424-ccdB) & \\
\hline YJH859 & sen 154::kanMX (SEN15 tiling block CEN ARS URA3) (pAG424-10x-tRNA) & \\
\hline YJH860 & sen34A::kanMX (SEN34 tiling block CEN ARS URA3) (pAG424-ccdB) & \\
\hline YJH861 & sen34A::kanMX (SEN34 tiling block CEN ARS URA3) (pAG424-10x-tRNA) & \\
\hline YJH862 & sen54A::kanMX (SEN54 tiling block CEN ARS URA3) (pAG424-ccdB) & \\
\hline YJH863 & sen54A::kanMX (SEN54 tiling block CEN ARS URA3) (pAG424-10x-tRNA) & \\
\hline YJH864 & HAC1-C-terminal-3x-FLAG & \\
\hline YJH865 & $\operatorname{tr} 11 \Delta::$ KanMX HAC1-C-terminal-3x-FLAG (pAG424-SUP4-10x-tRNA) & \\
\hline YJH866 & tpt1A::LEU2 HAC1-C-terminal-3x-FLAG (pAG424-SUP4-10x-tRNA) & \\
\hline
\end{tabular}

All strains are background W303 (MATa \{leu2-3,112 trp1-1 can1-100 ura3-1 ade2-1 his3-11,15\}).

G-25 Sephadex (GE) spin columns. Probes were heated to $100^{\circ} \mathrm{C}$ and diluted into $10 \mathrm{~mL}$ ULTRAhyb Oligo hybridization buffer (Life Technologies). Total RNA (normalized to SCR1 loading) was electrophoresed, along with RiboRuler Low Range RNA Ladder (Thermo) and ss10 ssDNA ladder (Simplex Sciences) on precast $10 \%$ polyacrylamide urea TBE Novex gels (Life Technologies) at $160 \mathrm{~V}$ for $90 \mathrm{~min}$. Gels were stained with SybrGold Nucleic Acid Stain (Life Technologies), imaged, and electrotransferred with a Genie electroblotter (Idea Scientific) onto Hybond N+ nylon membranes (GE) at $19 \mathrm{~V}$ for $60 \mathrm{~min}$ submerged in $1 \times$ TBE. RNA was crosslinked to the membranes with $0.12 \mathrm{~J}$ of $254 \mathrm{~nm}$ UV light (Stratalinker 1800, Stratagene). Nylon membranes were blocked with $10 \mathrm{~mL}$ ULTRAhyb Oligo for $1 \mathrm{~h}$ at $42^{\circ} \mathrm{C}$ and hybridized with probe at $42^{\circ} \mathrm{C}$ for $18 \mathrm{~h}$. Blots were washed at $42^{\circ} \mathrm{C}$ for $30 \mathrm{~min}$ each with buffer ( $2 \times$ SSC, $0.1 \%$ SDS) and were developed by phosphorimaging (GE, Molecular Dynamics).

\section{Detection of $2^{\prime}$-phosphate linkages by RT-PCR}

A reverse primer that anneals directly downstream from the $2^{\prime}$ phosphate site (Table 3, HAC1-R0 2-P) was designed so that the first deoxyribonucleotide incorporated by the reverse transcriptase is complementary to the $2^{\prime}$-phosphorylated ribonucleotide. Total RNA $(2 \mu \mathrm{g})$ was DNased (Turbo DNase Kit, Ambion), treated \pm with calf intestinal phosphatase (NEB), and acid-phenol extracted. DNased and \pm CIP-ed total RNA was denatured at $65^{\circ} \mathrm{C}$ for $5 \mathrm{~min}$ with $10 \mathrm{pmol}$ of the reverse primer and then transferred to ice. The concentration of dNTPs in reverse transcription reactions was reduced from 500 to $1 \mu \mathrm{M}$ to inhibit reverse transcriptase (SuperScript III, Life Technologies, lot \#1826824) at sites of $2^{\prime}$-phosphorylation (Fig. 4E, schematic). PCR was performed with the same reverse primer and a forward primer that anneals to the $5^{\prime}$-exon of HAC1; 28 cycles were performed on low dNTP reactions and 22 
TABLE 3. Oligonucleotide sequences

\begin{tabular}{ll}
\hline Oligonucleotide name & \multicolumn{1}{c}{ Oligonucleotide sequence $\left(5^{\prime} \rightarrow 3^{\prime}\right)$} \\
\hline tRNA Ile UAU 5-Exon N Probe & TATAAGCACGAAGCTCTAACCACTGAGCTACACGAGC \\
tRNA Ile UAU Intron N Probe & CGTTGCTTTTAAAGGCCTGTTTGAAAGTCTTTGGCACAGAAACTT \\
Phe-GAA-5-Exon-Probe & CTTCAGTCTGGCGCTCTCCCAACTGAGCTAAATCCGC \\
Leu-CAA-5-Exon-Probe & CTTGAATCAGGCGCCTTAGACCGCTCGGCCAAACAACC \\
Pro-UGG-5-Exon-Probe & CCCAAAGCGAGAATCATACCACTAGACCACACGCCC \\
Tyr-GUA-5-Exon-Probe & TTACAGTCTTGCGCCTTAAACCAACTTGGCTACCGAGAG \\
HAC1-F RT-PCR & ACCTGCCGTAGACAACAACAAT \\
HAC1-R RT-PCR & AAAACCCACCAACAGCGATAAT \\
HAC1-F 2-P RT-PCR & ATGGGAGCTGCAGATGTTTAAG \\
HAC1-RO 2-P & GAATTCAAACCTGACTGCGCTT \\
TPT1-F RT-PCR & TGTTCAGGTCGCTCAATAATGT \\
TPT1-R RT-PCR & TCTTTTCGAGCGGTATGTTTCT \\
TRL1-F2 RT-PCR & GTGGCAGAATATTGCGATGA \\
TRL1-R2 RT-PCR & ATCCTCCAAGGTGTTCGATG \\
KAR2-QPCR-F & AAGACAAGCCACCAAGGATG \\
KAR2-QPCR-R & AGTGGCTTGGACTTCGAAAA \\
PGK1-QPCR-F & TCTTAGGTGGTGCCAAAGGTT \\
PGK1-QPCR-R & GCCTTGTCGAAGATGGAGTC \\
HAC1-PML104-plus & GATCTTCATGAAGACAATCGCAAGGTTTTAGAGCTAG \\
HAC1-PML104-minus & CTAGCTCTAAAACCTTGCGATTGTCTTCATGAA \\
\hline
\end{tabular}

cycles were performed on RT reactions with normal dNTP concentrations. Amplified DNA was electrophoresed in a $2 \%$ agarose TBE $1 \times$ SybrGold (Life Technologies) gel and imaged.

\section{Expression vector for intronless tRNAs}

We designed a sequence to express 10 prespliced tRNAs using the SUP4 promoter and RPR1 terminator, respectively (Good and Engelke 1994). The full sequence is available in Supplemental Material and Addgene record 70125. Two restriction sites at the $5^{\prime}$ and $3^{\prime}$ ends of the sequence for SacI and ClaI are underlined. Ten tRNA genes are encoded with an intervening spacer ("CTTTGT") derived from a dicistronic tRNA (Engelke et al. 1985). From $5^{\prime}$ to $3^{\prime}$, the tRNAs are: Phe(GAA), Leu(CAA), Lys(UUU), Ser(GCU), Ile(UAU), Trp(CCA), Tyr(GUA), Pro(UGG), Ser(CGA), and Leu (UAG). The Pol III promoter contains sequence elements within the SUP4 Tyr(GUA) tRNA (Good and Engelke 1994), and thus tRNA $^{\text {Tyr(GUA) }}$ occurs twice in the construct. The sequence was synthesized as a gBlock from IDT and recombined into pDONR22 1 in a Gateway BP reaction (Life Technologies). The product plasmid (pDONR221-10X-tRNA) was recombined by a Gateway LR reaction into pAG424- $c c d B$ (created by removing the GPD promoter from pAG424-GPD-ccdB[Alberti et al. 2007]), which has the TRP1 selectable marker and a $2 \mu$ origin for high-copy number per cell (Chan et al. 2013). The pDONR221-10X-tRNA, pAG424- $c c d B$ (empty vector), and pAG424-10X-tRNA plasmids are available from Addgene (plasmids 70125, 70124, and 70123).

\section{HAC1 epitope tagging and western blotting}

Oligonucleotide probes HAC1-pML104-plus and HAC1-pML104minus (IDT) (Table 3) form an insert that was ligated into the Cas 9 and sgRNA yeast expression plasmid pML104 (Addgene entry 67638) (Laughery et al. 2015). Yeast strains were simultaneously transformed with pML104-HAC1-ct and FLAG donor DNA with homology to the HAC1 gene for homology-directed repair. Cotransformed yeast were selected on uracil drop-out media (US Biologicals) and confirmed to have an in-frame FLAG epitope tag by Sanger sequencing. Cell lysates were analyzed by immunoblotting using an anti-FLAG M2 antibody (Sigma) and secondary antimouse HRP-conjugated antibodies (ThermoFisher Scientific) with Enhanced Chemiluminescence detection (Promega). Loading controls included Ponceau staining of the membrane and antiGAPDH antibody (UBP-Bio).

\section{SUPPLEMENTAL MATERIAL}

Supplemental material is available for this article.

\section{ACKNOWLEDGMENTS}

We thank B. Schwer and S. Shuman for providing yeast strains, and D. Engelke and E. Phizicky for comments on the manuscript. This study was funded in part by grants from the National Institutes of Health (R35 GM119550 to J.H. and T32 GM008730 to P.D.C. and L.K.W.) and the RNA Bioscience Initiative at the University of Colorado School of Medicine (RNA Scholars Award to P.D.C.).

Received May 25, 2017; accepted December 4, 2017.

\section{REFERENCES}

Alberti S, Gitler AD, Lindquist S. 2007. A suite of Gateway cloning vectors for high-throughput genetic analysis in Saccharomyces cerevisiae. Yeast 24: 913-919.

Amitsur M, Levitz R, Kaufmann G. 1987. Bacteriophage T4 anticodon nuclease, polynucleotide kinase and RNA ligase reprocess the host lysine tRNA. EMBO J 6: 2499-2503.

Birkedal U, Christensen-Dalsgaard M, Krogh N, Sabarinathan R, Gorodkin J, Nielsen H. 2015. Profiling of ribose methylations in 
RNA by high-throughput sequencing. Angew Chem Int Ed Engl 54: 451-455.

Burroughs AM, Aravind L. 2016. RNA damage in biological conflicts and the diversity of responding RNA repair systems. Nucleic Acids Res 44: 8525-8555.

Chakravarty AK, Subbotin R, Chait BT, Shuman S. 2012. RNA ligase RtcB splices $3^{\prime}$-phosphate and $5^{\prime}-\mathrm{OH}$ ends via covalent RtcB-(histidinyl)-GMP and polynucleotide- $\left(3^{\prime}\right) \mathrm{pp}\left(5^{\prime}\right) \mathrm{G}$ intermediates. Proc Natl Acad Sci 109: 6072-6077.

Chan KM, Liu YT, Ma C-H, Jayaram M, Sau S. 2013. The 2 micron plasmid of Saccharomyces cerevisiae: a miniaturized selfish genome with optimized functional competence. Plasmid 70: 2-17.

Chan PP, Lowe TM. 2009. GtRNAdb: a database of transfer RNA genes detected in genomic sequence. Nucleic Acids Res 37: D93-D97.

Culver GM, McCraith SM, Zillmann M, Kierzek R, Michaud N, LaReau RD, Turner DH, Phizicky EM. 1993. An NAD derivative produced during transfer RNA splicing: ADP-ribose $1^{\prime \prime}-2$ " cyclic phosphate. Science 261: 206-208.

Dhungel N, Hopper AK. 2012. Beyond tRNA cleavage: novel essential function for yeast tRNA splicing endonuclease unrelated to tRNA processing. Genes Dev 26: 503-514.

Di Santo R, Aboulhouda S, Weinberg DE. 2016. The fail-safe mechanism of post-transcriptional silencing of unspliced HAC1 mRNA. Elife 5: e20069.

Engelke DR, Gegenheimer P, Abelson J. 1985. Nucleolytic processing of a tRNA ${ }^{\text {Arg }}$-tRNA ${ }^{\text {Asp }}$ dimeric precursor by a homologous component from Saccharomyces cerevisiae. J Biol Chem 260: 1271-1279.

Galli G, Hofstetter H, Birnstiel ML. 1981. Two conserved sequence blocks within eukaryotic tRNA genes are major promoter elements. Nature 294: 626-631.

Gietz RD, Schiestl RH. 2007. High-efficiency yeast transformation using the LiAc/SS carrier DNA/PEG method. Nat Protoc 2: 31-34.

Gonzalez TN, Sidrauski C, Dörfler S, Walter P. 1999. Mechanism of non-spliceosomal mRNA splicing in the unfolded protein response pathway. EMBO J 18: 3119-3132.

Good PD, Engelke DR. 1994. Yeast expression vectors using RNA polymerase III promoters. Gene 151: 209-214.

Greer CL, Peebles CL, Gegenheimer P, Abelson J. 1983. Mechanism of action of a yeast RNA ligase in tRNA splicing. Cell 32: 537-546.

Grosjean H, Szweykowska-Kulinska Z, Motorin Y, Fasiolo F, Simos G. 1997. Intron-dependent enzymatic formation of modified nucleosides in eukaryotic tRNAs: a review. Biochimie 79: 293-302.

Harding HP, Lackey JG, Hsu HC, Zhang Y, Deng J, Xu RM, Damha MJ, Ron D. 2008. An intact unfolded protein response in Trptl knockout mice reveals phylogenic divergence in pathways for RNA ligation. RNA 14: 225-232.

Hopper AK. 2013. Transfer RNA post-transcriptional processing, turnover, and subcellular dynamics in the yeast Saccharomyces cerevisiae. Genetics 194: 43-67.

Jones GM, Stalker J, Humphray S, West A, Cox T, Rogers J, Dunham I, Prelich G. 2008. A systematic library for comprehensive overexpression screens in Saccharomyces cerevisiae. Nat Methods 5: 239-241.

Kirchner S, Ignatova Z. 2015. Emerging roles of tRNA in adaptive translation, signalling dynamics and disease. Nat Rev Genet 16: 98-112.

Kosmaczewski SG, Edwards TJ, Han SM, Eckwahl MJ, Meyer BI, Peach S, Hesselberth JR, Wolin SL, Hammarlund M. 2014. The RtcB RNA ligase is an essential component of the metazoan unfolded protein response. EMBO Rep 15: 1278-1285.

Laughery MF, Hunter T, Brown A, Hoopes J, Ostbye T, Shumaker T, Wyrick JJ. 2015. New vectors for simple and streamlined CRISPRCas9 genome editing in Saccharomyces cerevisiae. Yeast 32: 711-720.

Lopes RRS, Silveira Gde O, Eitler R, Vidal RS, Kessler A, Hinger S, Paris Z, Alfonzo JD, Polycarpo C. 2016. The essential function of the Trypanosoma brucei Trll homolog in procyclic cells is maturation of the intron-containing tRNA ${ }^{\text {Tyr }}$. RNA 22: 1190-1199.
Lu Y, Liang FX, Wang X. 2014. A synthetic biology approach identifies the mammalian UPR RNA ligase RtcB. Mol Cell 55: 758-770.

McCraith SM, Phizicky EM. 1990. A highly specific phosphatase from Saccharomyces cerevisiae implicated in tRNA splicing. Mol Cell Biol 10: 1049-1055.

Mori K, Sant A, Kohno K, Normington K, Gething MJ, Sambrook JF. 1992. A 22 bp cis-acting element is necessary and sufficient for the induction of the yeast KAR2 (BiP) gene by unfolded proteins. EMBO J 11: 2583-2593.

Nandakumar J, Schwer B, Schaffrath R, Shuman S. 2008. RNA repair: an antidote to cytotoxic eukaryal RNA damage. Mol Cell 31: 278-286.

Nikawa J, Akiyoshi M, Hirata S, Fukuda T. 1996. Saccharomyces cerevisiae IRE2/HAC1 is involved in IRE1-mediated KAR2 expression. Nucleic Acids Res 24: 4222-4226.

Ogawa N, Mori K. 2004. Autoregulation of the HAC1 gene is required for sustained activation of the yeast unfolded protein response. Genes Cells 9: 95-104.

Phizicky EM, Hopper AK. 2010. tRNA biology charges to the front. Genes Dev 24: 1832-1860.

Phizicky EM, Schwartz RC, Abelson J. 1986. Saccharomyces cerevisiae tRNA ligase. Purification of the protein and isolation of the structural gene. J Biol Chem 261: 2978-2986.

Schutz K, Hesselberth JR, Fields S. 2010. Capture and sequence analysis of RNAs with terminal 2',3'-cyclic phosphates. RNA 16: 621-631.

Schwer B, Sawaya R, Ho CK, Shuman S. 2004. Portability and fidelity of RNA-repair systems. Proc Natl Acad Sci 101: 2788-2793.

Sherman F. 2002. Getting started with yeast. Methods Enzymol 350: 3-41.

Sidrauski C, Cox JS, Walter P. 1996. tRNA ligase is required for regulated mRNA splicing in the unfolded protein response. Cell 87: 405-413.

Spinelli SL, Consaul SA, Phizicky EM. 1997. A conditional lethal yeast phosphotransferase (tpt1) mutant accumulates tRNAs with a $2^{\prime}$ phosphate and an undermodified base at the splice junction. RNA 3: $1388-1400$.

Steiger MA, Jackman JE, Phizicky EM. 2005. Analysis of 2'-phosphotransferase (Tptlp) from Saccharomyces cerevisiae: evidence for a conserved two-step reaction mechanism. RNA 11: 99-106.

Stevens A. 2001. 5'-Exoribonuclease 1: Xrn1. In Methods in enzymology (ed. Nicholson AW), Vol. 342, pp. 251-259. Academic Press, NY.

Temmel H, Müller C, Sauert M, Vesper O, Reiss A, Popow J, Martinez J, Moll I. 2016. The RNA ligase RtcB reverses MazF-induced ribosome heterogeneity in Escherichia coli. Nucleic Acids Res 45: 4708-4721.

Trotta CR, Miao F, Arn EA, Stevens SW, Ho CK, Rauhut R, Abelson JN. 1997. The yeast tRNA splicing endonuclease: a tetrameric enzyme with two active site subunits homologous to the archaeal tRNA endonucleases. Cell 89: 849-858.

Tsuboi T, Yamazaki R, Nobuta R, Ikeuchi K, Makino S, Ohtaki A, Suzuki Y, Yoshihisa T, Trotta C, Inada T. 2015. The tRNA splicing endonuclease complex cleaves the mitochondria-localized CBP1 mRNA. J Biol Chem 290: 16021-16030.

Wang P, Selvadurai K, Huang RH. 2015. Reconstitution and structure of a bacterial Pnkp1-Rnl-Hen1 RNA repair complex. Nat Commun 6: 6876.

Whipple JM, Lane EA, Chernyakov I, D'Silva S, Phizicky EM. 2011. The yeast rapid tRNA decay pathway primarily monitors the structural integrity of the acceptor and T-stems of mature tRNA. Genes Dev 25: 1173-1184.

Winey M, Mendenhall MD, Cummins CM, Culbertson MR, Knapp G. 1986. Splicing of a yeast proline tRNA containing a novel suppressor mutation in the anticodon stem. J Mol Biol 192: 49-63.

Wu P, Brockenbrough JS, Paddy MR, Aris JP. 1998. NCL1, a novel gene for a non-essential nuclear protein in Saccharomyces cerevisiae. Gene 220: 109-117.

Wu J, Hopper AK. 2014. Healing for destruction: tRNA intron degradation in yeast is a two-step cytoplasmic process catalyzed by tRNA ligase Rlg1 and 5'-to-3' exonuclease Xrn1. Genes Dev 28: 1556-1561. 

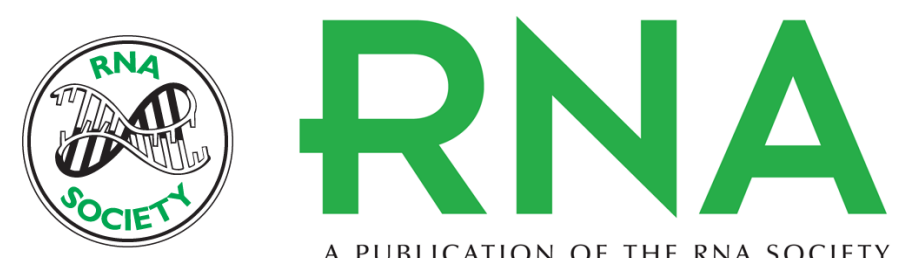

A PUBLICATION OF THE RNA SOCIETY

\title{
Genetic bypass of essential RNA repair enzymes in budding yeast
}

\author{
Patrick D. Cherry, Laura K. White, Kerri York, et al.
}

RNA 2018 24: 313-323 originally published online December 6, 2017

Access the most recent version at doi:10.1261/rna.061788.117

Supplemental Material

References

Creative Commons License

Email Alerting Service
http://rnajournal.cshlp.org/content/suppl/2017/12/06/rna.061788.117.DC1

This article cites 47 articles, 19 of which can be accessed free at: http://rnajournal.cshlp.org/content/24/3/313.full.html\#ref-list-1

This article is distributed exclusively by the RNA Society for the first 12 months after the full-issue publication date (see http://rnajournal.cshlp.org/site/misc/terms.xhtml). After 12 months, it is available under a Creative Commons License (Attribution-NonCommercial 4.0 International), as described at http://creativecommons.org/licenses/by-nc/4.0/.

Receive free email alerts when new articles cite this article - sign up in the box at the top right corner of the article or click here.

To subscribe to $R N A$ go to:

http://rnajournal.cshlp.org/subscriptions 